\title{
ИНСУЛИНОПОДОБНЫЙ ФАКТОР РОСТА-1 И АДИПОКИНЫ У ДЕТЕЙ, РОЖДЁННЫХ ОТ МАТЕРЕЙ С ОЖИРЕНИЕМ
}

\author{
Л.С. Алавердян ${ }^{1,2}$, Л.Я.Климов', В.О.Курьянинова', Р.А. Атанесян ${ }^{3}$, Р.И.Аракелян ${ }^{3}$, Т.А. Углова ${ }^{3}$ \\ 'Кафедра педиатрии Ставропольского государственного медицинского университета, Россия, \\ Ставрополь, \\ ${ }^{2}$ Ставропольский краевой клинический перинатальный чентр, Россия, Ставрополь \\ ${ }^{3}$ Кафедра эндокринологии и детской эндокринологии Ставропольского государственного \\ медицинского университета, Россия, Ставрополь
}

Неуклонный рост числа взрослых пациентов с ожирением в мире, также прогрессивное увеличение числа детей и подростков с избыточной массой тела и ожирением обуславливает актуальность теории нутритивного программирования. Безусловно, характер питания ребенка в критические периоды жизни предопределяет особенности его метаболизма на протяжении всей последующей жизни и, как следствие, предрасположенность к определенным заболеваниям. Необходимо отметить, что одним из наиболее важных таких периодов является внутриутробный период, и именно характер питания матери программирует многие особенности метаболизма у будущего ребенка.

В последние десятилетия в литературе появляется, все больше информации о гормональных свойствах жировой ткани и их роли в патогенезе метаболических нарушений. Очевидным также является также тот факт, что у детей, рожденных от матерей с ожирением, риск развития метаболических нарушений в последующей жизни выше. Однако до конца не изучены механизмы и лабораторные предикторы, определяющие метаболические нарушения у плода во внутриутробном периоде. Нарушение у матери секреции ряда продуктов адипоцитов, в частности адипокинов, вероятнее всего вносит непоправимый вклад в особенности метаболизма плода и соответственно будущего ребенка.

Одним из наиболее изученных адипокинов является лептин. Увеличение массы жировой ткани сопровождается повышением уровня лептина, однако по неизвестным причинам его эффекты, направленные на снижение массы тела, не реализуются. Другим не менее важным гормоном является грелин - пептид, стимулирующий потребление пищи, который синтезируется энтероэндокринными P/D1-клетками желудка и тонкого кишечника. Важно отметить, что наряду с непосредственным участием в регуляции метаболизма, грелин также контролирует поступление и использование нутриентов через стимуляцию выработки гормона роста, который, в свою очередь, стимулирует синтез инсулиноподобного фактора роста (ИФР) в печени - важнейшего медиатора регуляции метаболизма. У пациентов с избыточной массой тела и ожирением отмечаются высокие уровни грелина.

ЦЕЛЬ: проспективный анализ влияния эндокринного статуса матери на уровень адипокинов и соматомедина С или ИФР-1 у новорожденных детей, также оценка антропометрических данных новорожденных детей.

МЕТОДЫ: проанализированы 124 новорождённых в возрасте 3-х суток жизни. Дети были разделены на 2 группы: 1-я группу составили 84 новорождённых от матерей с ожирением, 2-я группа (контрольная) - 40 детей от здоровых матерей. Адипокины и соматомедин С определялись у новорожденных с помощью иммуноферментного анализа.

РЕЗУЛЬТАТЫ: массо-ростовые показатели у 64,3\% (54) новорожденных от матерей с ожирением были выше 90-го процентиля, тогда как в группе детей от здоровых матерей показатели роста и веса не выходили за пределы гестационной нормы. Анализ показал, что уровень лептина прямо пропорционален массе тела у исследуемых детей, так в 1-й группе его уровень составил

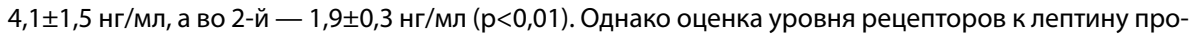
демонстировала противоположную картину, а именно у детей с макросомией этот показатель составил 43,5 $\pm 3,7$ нг/мл, а у новорождённых с нормосомией $-29,0 \pm 3,97$ нг/мл ( $<<0,05)$. Уровень грелина у детей от здоровых матерей и детей, рожденных от матерей с ожирением достоверно 


\section{СБОРНИК ТЕЗИСОВ}

XVII Российская научно-практическая конференция детских эндокринологов «Достижения науки в практику детского эндокринолога»

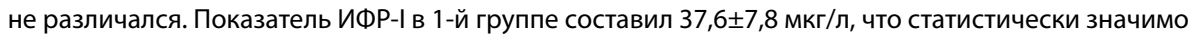

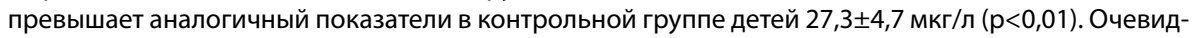
но, что повышенный уровень ИФР-1 объясняет макросоматические параметры у детей, рожденных от матерей с ожирением различной степени.

Выводы: таким образом, дети, рожденные от матерей с ожирением различной степени, имеют клинические и лабораторные признаки метаболических нарушений, в частности макросомию, повышенный уровень лептина и повышенные значения ИФР-1. Вероятно, данные изменения ассоциированы с особенностями метаболизма, возникающими у детей, рожденных от матерей с ожирением, что в последующем при влиянии факторов внешней среды определяет ожирение и нарушения углеводного обмена. 